\title{
Help from the Animal Technician
}

\author{
W. R. Kingston
}

For many seriously endangered animals captive breeding seems to be the last hope of saving them. Many zoos are trying to do this, but, with some exceptions, without great success so far. The author of this article suggests that conservationists are not making use of the highly skilled animal technicians in laboratories and research stations who could certainly achieve good breeding success with many species at comparatively small cost.

Conservation in the broadest sense is as much a matter for concern to animal technicians as to the rest of the human race. We are, however, animal technicians, and it seems reasonable to assume that we chose this profession because of an innate interest and liking for animals, for if we came into it only for the big money and easy life the majority of us would have been rapidly disillusioned. Our livelihood, therefore, and that of many of our scientific colleagues and employers, is dependant on the animal kingdom. If only for this reason and the uses for which laboratory animals are required we should all be especially concerned with those aspects of conservation relating to animals and in particular the survival of endangered species, an area where surely we have much to offer.

Many of us are concerned with the actual breeding of animals for research and this may well include difficult species such as Chinese hamsters and cotton rats and, particularly in cancer research, especially difficult inbred strains which may be delicate, reproductively almost sterile and highly susceptible to disease. Nevertheless we have acquired the expertise and accumulated knowledge required for their production and maintenance in the required genetic status. If any research establishment found that the most suitable animal was only obtainable by breeding, there is little doubt that, however exotic that animal might be, it would be produced in a comparatively short time and a continuous supply ensured.

It seems a great pity however, that the conservationists, although unquestionably extremely well motivated and intentioned, do not apply the same expertise to the breeding of endangered species. As an example of what I mean I would like to use a little primate, the golden lion marmoset Leontopithecus rosalia. (Photograph on page 437).

This almost incredibly beautiful little animal was once widespread in south-east Brazil but is now reduced to a very small area estimated to contain only around five hundred animals. This has been caused by destruction of the habitat for timber and roads, and the saleability at high prices of these animals in the exotic pet trade,

W. R. Kingston is an animal technician on the staff of Fisons Pharmaceutical Division's Hillcrest Research Station. This paper was read to the 1973 Exeter Congress of the Institute of Animal Technicians. 
particularly in the USA. The danger was realised in 1969 and an embargo on its import into the USA was imposed and more recently on its export from Brazil. A breeding programme was set up at the San Diego Zoo (three pairs of animals), a number of conferences were held at which the plight of this animal was discussed and a special 'Save the Lion Marmoset' symposium held in Washington DC in February 1972, under the auspices of the Wild Animal Propagation Trust. The International Union for Conservation of Nature (IUCN) was approached and WWF provided funds for the purchase of an area in which the lion marmoset is still found to create a reserve there. Some animals were collected from areas being rapidly destroyed and they are being set up to breed in enclosures in a Brazilian park. Known owners of captive animals in the USA have been approached to attempt to arrange by exchange and collaboration the maximum breeding potential.

All this may seem very impressive but what has actually been achieved? At the end of the first three years the San Diego Zoo had lost some of the adults and had not successfully reared any young. The reserve is ideal, but it is too large to fence and money is not available to patrol it adequately. The local inhabitants, even if literate, are not likely to respect a few notices and poaching will continue - of the animals for food and sale, and of the habitat for timber. A number of young have been bred in zoos and by private owners but these are decreasing. Meanwhile the breeding animals are becoming senile and the second generation young have not as yet been bred.* The future for this animal looks very bleak indeed.

In the past few years research workers have been showing increased interest in marmosets as small, relatively inexpensive primates with several special characteristics of considerable potential value. Great strides have been made in finding out how to keep them successfully and, because of the unsatisfactory supply and condition of imported animals, to breed them under laboratory conditions. Pioneered by Levy, Artecona, Hampton and Deinhardt in the USA, there are now a number of colonies established in America and the UK, and ICI are currently setting up a colony to breed a thousand per year. This work is mainly confined to three species, the common marmoset Callithrix jacchus, the white-lipped tamarin Saguinus nigricollis, and the cotton-topped marmoset Saguinus oedipus, but several others have been bred in small numbers. This experience coupled with the limited work on lion marmosets and the general similarity of the family's thirty-five species leaves little doubt that the lion marmoset could be bred as easily under similar conditions.

I am suggesting therefore, that this species could be saved for the scientific, aesthetic and pleasurable benefit of future generations of mankind for very much less cost than that already expended by breeding under controlled conditions, and that this would soon achieve the first essential of conservation of a species, the survival of a genetically viable, self-propagating colony. The requirements are:

* Two pairs of twins born at the Los Angeles Zoo in 1973 and one pair at the National Zoo, Washington, were second-generation births. Editors 
1. Two rooms or buildings each around $400 \mathrm{sq} \mathrm{ft}$ situated perhaps at zoos or safari parks, one for economy's sake in the tropics and the other in the USA or Europe. They would require standard heating and ventilation and the usual services. Purpose built, the cost would depend on the material used but should not exceed $£ 2000$ each. 2. Cages and ancillary equipment for each room, at a maximum cost of $£ 500$ ( $£ 1000$ in all).

3. Part-time (two hours daily) services of a reasonably trained animal technician/zoo keeper/volunteer.

4. Supervision by a suitably experienced person and availability of a veterinary surgeon.

5. Twenty-five pairs of animals, the cost of which, if obtained by the IUCN, would be that of catching and transport only.

The revenue costs in Britain, including depreciation, wages, heat, light and food should not exceed $£ 1500$ per annum and much less in the tropics, say $£ 2500$ overall.

I would be very disappointed if at least thirty young were not successfully reared annually. They would be at the disposal of the IUCN though, of course, enough would need to be retained to ensure successive generations with careful control of genetics. Surplus animals could be used to stock controllable small reserves in suitable climates anywhere and I can see no reason why the remainder should not be sold to zoos all over the world who would certainly be willing to pay a good price for such an excellent exhibit. Once viable reserves were established in conditions where their continuity and permanent integrity was assured the original colony could be phased out and the facilities used for some other species.

There are many other species of marmoset, prosimians, especially the lemurs and higher primates in a similar desperate position. In view of their phylogenetic relationship to man and their immense and unique value in research over a wide field I should have thought that they would be of special concern to everyone. Practically without exception all have been bred in captivity and there is no doubt whatsoever that they could be bred in adequate numbers to ensure their permanent survival if really practical programmes were instituted. Perusal of the rare animal breeding records in the International Zoo Year Book proves this point but also highlights the total inadequacy overall of the highly commendable efforts of individual zoos. The isolated rearing of one young animal, while it may prolong for some years the existence of a living example of the species, has a somewhat hollow ring if in the meantime the species has become extinct. Even if a number are reared the $F 2$ generation is surely going to be a highly inbred strain with concomitant risk of lethal gene accumulation which must be true of some of the apparent outstanding successes, such as Sir Peter Scott's nene geese. According to the work of Falconer and other geneticists twenty unrelated breeding pairs are required to establish a random-bred colony and future generations should be bred from young animals contributed equally by all these pairs if a viable colony of adequate heterozygosity is to be maintained. 
These criteria are relatively simple to achieve in small animals and birds whose ecological requirements are not too highly specialised and these include literally hundreds of endangered species. The sheer physical dimensions of such species as gorilla, orang-utan, Sumatran rhinoceros, Indian lion and tiger, to mention a few, make them a much more difficult problem. Reserves in endemic habitats seem the obvious answer but political and economic pressures in the relatively undeveloped countries in which many of the species occur are so serious as to make them of doubtful long-term values unless they are large and attractive enough to be a national asset as a tourist attraction. With proper planning and organisation by the IUCn however, it should still be possible to fulfil the criteria set out above by using the world's zoos which, in return for the exhibition value, would surely accept some control. A pair of animals at each of twenty zoos could be managed as one colony.

To sum up therefore, I am suggesting that a practical attitude such as we are all accustomed to in the laboratory animal field might make more effective use of the resources of the IUCN than is currently being achieved. To my mind the important thing is to prevent the irretrievable loss of as many species as possible, and when this has been achieved it is time enough to consider more aesthetic, nationalistic and generally idealistic solutions to a problem of the utmost urgency.

\section{Back to China}

Early this year two pairs of Père David's deer bred at Whipsnade were sent to Peking in exchange for pairs of Manchurian and white-naped cranes by the Zoological Society of London. Since the original Pere David's deer stock were killed in the Boxer Rebellion at the beginning of the century there have been none in China, apart from two pairs sent from London in 1956, of which only one animal survives. It is hoped that the animals sent this year will form the nucleus of a new herd in the enclosed park of the old Imperial Palace in Peking. They were sent by air to Hong Kong and thence by train.

\section{Correction}

John MacKinnon, author of the article on Orang-utans in Sumatra, in Oryx, October, 1973, asks us to correct mistakes in Table 1, Page 235. This should read:

Orang-utan densities in North Sumatra (minimal)

West Langkat (Berkail river)

Ranun south

Ranun north

Sikundur

Ketambe more than 1 per sq.km. about 1 per sq.km. less than 1 per sq.km. less than 1 per sq.km. more than 1 per sq.km. 